\title{
Rural community attitude towards mental healthcare: a mixed-method study in Khurda district of Odisha, India
}

\author{
Sunita Jena ${ }^{1}$, Krushna Chandra Sahoo ${ }^{2 *}$, Mousumi Samal ${ }^{2}$, P. Kripalini ${ }^{2}$, Chandni Shrivastava $^{3}$, Henanee Anand ${ }^{4}$, \\ Pranab Mahapatra ${ }^{5}$ and Sanghamitra Pati ${ }^{2}$
}

\begin{abstract}
Background: Mental health is a global concern due to its hasty escalation. The shifting social dynamics in rural India intensify care-seeking behaviors, which means immediate action is required. Mental illness, however, is seen as a neglected disorder. This study examined the attitude of rural people towards mental health care in rural Odisha, India. An explanatory mixed-method study was conducted among 395 participants age between 18 to 65 years in two rural blocks of Khurdha district, Odisha. A total of 16 in-depth interviews were conducted among the caretakers of the patients.

Results: The educational level, religion, age, and gender $(p<0.05)$ had significantly associated with attitudes towards mental healthcare facilities; female having lower-education had more negative attitudes towards mental healthcare facilities. The major barriers for the mental healthcare were the rejection of mental illness by patients due to fear of societal stigma, faith on religious healers, and lack of availability of mental health services.

Conclusions: Perspective of people should be considered along with their location, gender, and education when strategizing the psychiatric healthcare system as their perception/attitude serves as facilitators/barriers for achieving mental healthcare goals and psychiatric hospital goals.
\end{abstract}

Keywords: Attitude, Stigma, Mental healthcare, Religious healers

\section{Background}

Mental health is a global concern due to its hasty escalation. Globally, about $29 \%$ of individuals have experienced any kind of mental disorder in their lifetime. The global burden of mental and neurological disorders accounted for more than 7\% in 2016 [14].The previous study showed that one-fifth of psychiatric patients worldwide are said to be living in the South Asian region, particularly China and India. Approximately 150 million people need emergency care due to psychiatric illness [20]. In India, the current estimated prevalence of mental disorder is 197.3 million people in 2017 [16], but

\footnotetext{
* Correspondence: sahookrushna@yahoo.com

${ }^{2}$ Regional Medical Research Centre, Indian Council of Medical Research, Bhubaneswar, Odisha 751023, India

Full list of author information is available at the end of the article
}

the budget allocation for mental health in India is extremely low [6].

In India, there are 0.004 psychiatric hospitals per 100 , 000 people and 2.1 psychiatric hospitals per 100,000 people [2]. In addition, in India, patients with mental illness prefer to receive treatment from medical practitioners and faith healers instead of seeking professional help [9]. A study from India found that about one-third of the respondents had poor mental health, and only $10 \%$ had sought mental health services [13]. Social stigma and superstitions associated with mental disorders are a major challenge to mental health policy and the program [8].The Mental Health Act was implemented in India in 2017. It is important to know people's attitudes towards mental health facilities; thus, lacuna will be detected and steps can be taken to

\section{Springer Open}

(c) The Author(s). 2020 Open Access This article is licensed under a Creative Commons Attribution 4.0 International License, which permits use, sharing, adaptation, distribution and reproduction in any medium or format, as long as you give appropriate credit to the original author(s) and the source, provide a link to the Creative Commons licence, and indicate if changes were made. The images or other third party material in this article are included in the article's Creative Commons licence, unless indicated otherwise in a credit line to the material. If material is not included in the article's Creative Commons licence and your intended use is not permitted by statutory regulation or exceeds the permitted use, you will need to obtain permission directly from the copyright holder. To view a copy of this licence, visit http://creativecommons.org/licenses/by/4.0/. 
improve the program. Therefore, a study was conducted to examine rural people's attitudes towards mental health in Odisha, India.

\section{Methods}

An explanatory mixed-methods study was conducted at Balianta and Balipatna blocks of Khurdha district, Odisha. A total of 20 villages were randomly selected-ten communities from each block. From each village, 20 participants, age between 18 to 65 years, were randomly selected. Equal numbers of female and male were selected. Total of 395 participants have participated in the quantitative interview. Five respondents (two male and three female) were not willing to take part in the study.

The validated questionnaire published by Gaebel et al. [3] was used to determine the attitudes of people towards mental healthcare and help-seeking behavior. The responses specified a 5-point Likert scale ranging from "definitely true" to "definitely not true." However, for the final analyses, we reduced the scale to three major categories: "agree" $(1,2)$, "undecided" (3), and "disagree" (4, 5). Negative attitudes were determined individually for each item, and depending on the item, a high or low score indicated more or fewer negative attitudes were decided. The sociodemographic characteristics such as age, gender, socioeconomic status, marital status, education level, religion, caste, and occupation were collected along with mental health questionnaires.

Statistical analysis was done using the Statistical Package for the Social Sciences software using the version SPSS v 22.0, Chicago, USA. Simple descriptive statistics were used for describing the characteristics of the study participants about their level of agreement, and disagreement level simple proportion analysis was performed. Categorical variables were expressed as counts (proportions). To find out the mean differences with respect to socio-demographic characteristics such as gender, religious belief was analyzed by using $t$ test for age, education, and religion. Analysis of variance-ANOVA-was used for analytical statistics, which was conducted with the seven items on the questionnaire as dependent variables, and gender as independent variable was used to find out the association between predictor variable and outcome variable among rural people. The $95 \% \mathrm{CI}$ with $p<0.05$ was taken as statistically significant. To see the impact of education, one-way ANOVA followed by Bonferroni post hoc test was used.

The in-depth interviews were conducted among the family caretakers of self-reported mental health problem participants $(n=16)$ to explore their health-seeking behaviors and practice. Among the ten were married female, and six were married male. The in-depth interviews were conducted in Odia language by first author and audio recorded. The audio recorded version was transcribed and translated into the English language. The data were analyzed using content analysis methods.

\section{Results}

This study included 395 rural respondents between the age group 18 to 65 years. The results depicted that $72.15 \%$ of the study participants were married. About $35 \%$ were having secondary education, followed by primary education (25\%), and no formal education (25\%). Around $62 \%$ of them were living in low socioeconomic conditions, and $85 \%$ of the respondents were living in a joint family.

Table 1 presents the association of public attitudes towards mental healthcare facilities (mean score of seven items) and socio-demographic characteristics.The educational level, religion, age, and gender $(p<0.05)$ had significantly associated with attitudes towards mental healthcare facilities. According to the mean score calculated, lower education levels (mean score $=2.31$ ) had more negative attitudes towards mental healthcare facilities than respondents with higher educational attainment (mean score $=$ 1.92 ) with $F=16.60$. It was also found that female respondents (mean score $=2.10$ ) had more negative attitudes than male respondents (mean score $=1.67$ and $t=-2.47$ ). While investigating the religion aspect, it was found that informants belonging to Hinduism are having more negative attitude (mean score $=2.18$ ) than respondents with other religion (mean score $=1.21$ ) with $F=11.10$. Age is also found to be statistically significant with value $F=2.37$.

Table 2 shows the attitudes towards mental healthcare facilities between male and female participants. The results showed that all of the items had more negative responses than positive. Furthermore, to know about the response with gender perspectives, female has more of a negative attitude than male towards mental healthcare facilities. According to female participants "psychiatric hospitals are just like prisons" $(p=0.01)$, and they also think that "once someone admitted to a psychiatric clinic, then it is very difficult to come out" $(p=<0.01)$. They also opined that at a psychiatric clinic "people are sedated rather than treated" $(p=0.02)$.

To see the impact of education, one-way ANOVA followed by Bonferroni post hoc test was used. This can be markedly depicted in Table 3 that illiterate people are having higher negative (mean score $=2.2$ ) attitude score with respect to gender, and it can be clearly shown that as the education increases, negative attitude decreases (mean score $=1.9$ ) with significant $p$ value $<0.001$. In case of public attitude score towards mental healthcare facilities by education level within age group, Table 4 describes that as education is increasing with the increase in age, public negative attitude is decreasing with $p$ value 0.001 .

The qualitative findings showed that people have a fear of electro-convulsive therapy. According to most of the 
Table 1 Association of public attitudes towards mental healthcare facilities and socio-demographic characteristics

\begin{tabular}{|c|c|c|c|c|}
\hline Socio-demographic characteristics & $N(\%)$ & $\begin{array}{l}\text { Score of public attitude } \\
\text { towards mental illness } \\
\text { mean [SD] }\end{array}$ & $\begin{array}{l}\text { Point estimate/test } \\
\text { statistics }\end{array}$ & $p$ value \\
\hline \multicolumn{5}{|l|}{ Gender } \\
\hline Male & $198(50)$ & $2.10[0.40]$ & $t=-2.47$ & $0.014^{*}$ \\
\hline Female & $197(50)$ & $2.21[0.43]$ & & \\
\hline \multicolumn{5}{|l|}{ Age in years } \\
\hline$>25$ & $60(15.19)$ & $1.98[0.45]$ & $F=2.54$ & $0.0037^{*}$ \\
\hline $25-34$ & $103(26.08)$ & $2.14[0.38]$ & & \\
\hline $35-44$ & $86(21.77)$ & $2.14[0.42]$ & & \\
\hline $45-54$ & $92(23.29)$ & $2.24[0.39]$ & & \\
\hline$\leq 55$ & $54(13.67)$ & $2.28[0.44]$ & & \\
\hline \multicolumn{5}{|l|}{ Education } \\
\hline Illiterate & $97(25)$ & $2.31[0.35]$ & $F=16.60$ & $<0.001^{*}$ \\
\hline Primary & $99(25)$ & $2.27[0.34]$ & & \\
\hline Secondary & $138(35)$ & $2.07[0.44]$ & & \\
\hline Graduation and above & $61(15)$ & $1.92[0.41]$ & & \\
\hline \multicolumn{5}{|l|}{ Strong religious belief } \\
\hline Yes & $325(82)$ & $2.16[0.42]$ & $t=-0.3021$ & 0.762 \\
\hline No & $70(18)$ & $2.17[0.39]$ & & \\
\hline \multicolumn{5}{|l|}{ Religion } \\
\hline Hinduism & $339(86)$ & $2.18[0.40]$ & $F=11.10$ & $<0.001^{*}$ \\
\hline Islam & $42(11)$ & $2.19[0.28]$ & & \\
\hline Christianity & $10(2)$ & $1.74[0.71]$ & & \\
\hline Others & $4(1)$ & $1.21[0.14]$ & & \\
\hline
\end{tabular}

$t=t$ test; $F=$ ANOVA

${ }^{*} p$ value $<0.05$ statistically significant

female participants, the mental health treatment means only electro-convulsive therapy, which makes them distress to mental health care at facilities. They came to know about electro-convulsive therapy through mass media, especially television. Most of the female participants viewed that the mental health facilities are just like prison, where a patient lives in isolation.

I had heard that they used to give an electric shock for treatment in mental hospitals. I am a living being, and it is not easy to tolerate high voltage current on my body. I don't want to take current in the name of treatment ... I saw from television, and they give current on the head which makes the people forget everything.

\section{Barriers to seek mental health care at mental health facilities}

The qualitative findings showed that there were four significant barriers among patients to seek attention from mental health care facilities. These factors were rejection of mental illness by patients due to fear of societal stigma, faith on magico-religious healers, lack of availability of mental health services, and poor socioeconomic conditions.

Lack of awareness and knowledge in mental health leads to delay in care-seeking. Most of the time, the participants are not accepting their mental illness, although their family members found the symptoms of mental disorder.

I am not mad; why should I go to a mental hospital. My body and mind both are absolutely fine. I don't think I need any psychiatric treatment.

Majority of the participants told that if they went to a mental hospital, the society would consider them like a mad. It will be difficult for their children to get married and even to live in a society with others. This factor leads them to seek care from unrecognized faith healers.

If I will go to a mental health facility everybody will get to know that I am having some psychological 
Table 2 Attitudes towards mental health care facilities between male and female

\begin{tabular}{|c|c|c|c|c|c|c|}
\hline $\begin{array}{l}\text { Item } \\
\text { No. }\end{array}$ & Items on the measurement of attitude towards mental health care facilities & $\begin{array}{l}\text { Response } \\
\text { category }\end{array}$ & $\begin{array}{l}\text { Male } \\
N=198\end{array}$ & $\begin{array}{l}\text { Female } \\
N=197\end{array}$ & $\begin{array}{l}X^{2} \\
(\mathrm{df})\end{array}$ & $\begin{array}{l}p \\
\text { value }\end{array}$ \\
\hline \multirow[t]{3}{*}{1} & \multirow{3}{*}{$\begin{array}{l}\text { Treatment in a psychiatric hospital is out of question. On the contrary, one becomes } \\
\text { really sick there. }\end{array}$} & Agree & 104 & 118 & \multirow{3}{*}{$\begin{array}{l}3.74 \\
(2)\end{array}$} & \multirow[t]{3}{*}{0.154} \\
\hline & & Undecided & 34 & 36 & & \\
\hline & & Disagree & 60 & 43 & & \\
\hline \multirow[t]{3}{*}{2} & \multirow{3}{*}{$\begin{array}{l}\text { Psychiatric hospitals are hospitals just like other hospitals, the difference being that } \\
\text { mental illnesses and not physical illnesses are treated there }\end{array}$} & Agree & 64 & 51 & \multirow{3}{*}{$\begin{array}{l}2.35 \\
(2)\end{array}$} & \multirow[t]{3}{*}{0.308} \\
\hline & & Undecided & 43 & 44 & & \\
\hline & & Disagree & 90 & 103 & & \\
\hline \multirow[t]{3}{*}{3} & \multirow[t]{3}{*}{ Psychiatric hospitals have more in common with prisons than with hospitals } & Agree & 100 & 135 & \multirow{3}{*}{$\begin{array}{l}6.81 \\
(2)\end{array}$} & \multirow[t]{3}{*}{$0.015^{*}$} \\
\hline & & Undecided & 43 & 35 & & \\
\hline & & Disagree & 55 & 47 & & \\
\hline \multirow[t]{3}{*}{4} & \multirow[t]{3}{*}{ Psychiatric hospitals provide the necessary security to deal with a mental crisis } & Agree & 114 & 112 & \multirow{3}{*}{$\begin{array}{l}3.26 \\
(2)\end{array}$} & \multirow[t]{3}{*}{0.196} \\
\hline & & Undecided & 54 & 43 & & \\
\hline & & Disagree & 30 & 42 & & \\
\hline \multirow[t]{3}{*}{5} & \multirow{3}{*}{$\begin{array}{l}\text { Once you are admitted to a psychiatric clinic, then it is very difficult to come out again, } \\
\text { regardless of whether you are ill or not }\end{array}$} & Agree & 91 & 122 & \multirow{3}{*}{$\begin{array}{l}7.13 \\
(2)\end{array}$} & \multirow{3}{*}{$\begin{array}{l}< \\
0.01 *\end{array}$} \\
\hline & & Undecided & 23 & 31 & & \\
\hline & & Disagree & 84 & 24 & & \\
\hline \multirow[t]{3}{*}{6} & \multirow[t]{3}{*}{ People are not treated in the psychiatric hospital but only sedated. } & Agree & 101 & 125 & \multirow{3}{*}{$\begin{array}{l}6.53 \\
(2)\end{array}$} & \multirow[t]{3}{*}{$0.021 *$} \\
\hline & & Undecided & 38 & 29 & & \\
\hline & & Disagree & 59 & 43 & & \\
\hline \multirow[t]{3}{*}{7} & \multirow[t]{3}{*}{ Psychiatric hospitals are necessary to protect the society from the mentally ill patients } & Agree & 105 & 116 & \multirow{3}{*}{$\begin{array}{l}1.95 \\
(2)\end{array}$} & \multirow[t]{3}{*}{0.37} \\
\hline & & Undecided & 57 & 45 & & \\
\hline & & Disagree & 36 & 36 & & \\
\hline
\end{tabular}

Numbers in parentheses indicate column percentages

$x^{2}$ Chi square test statistic, $d f$ degrees of freedom

${ }^{*} p<0.05$

issues and they consider me as mad. I am an unmarried girl, then nobody will marry me, and noone will allow their children to play with me. It is better not to seek care from mental health facilities.

Hence, I choose to go to a faith healer.

Most of them had blind beliefs and prefers weapons of prayers and magic to cure of mental disorder. Some participants responded that they did not have any medical problem for which they did not go to seek care from the hospital. According to them, the mental health is a spiritual problem. They preferred to go to the faith healers assuming black magic from their relatives or neighbors.

Doctors prescribed medicines don't work on me. I always prefer the holy water given by tantrik [magico-religious healers].

The availability of specialized services and providers was also an obstacle for seeking appropriate mental health care at facilities. All the participants expressed that the mental health doctors are present only at district hospitals. They have to travel a long distance to reach district hospitals. Some people were unable to differentiate between a general practitioner and a specialist. According to them, every doctor can treat each health problem for which they prefer to go to a nearby health care facility like a primary health center in rural areas, where there is no psychiatrist. They requested for the psychiatric health campaign and demand for availability of psychiatric services in their local hospitals.

In our hospital, there is no mental doctor! How could we know about this? If there will be a doctor in our hospital, then only we can know about mental diseases and seek care.

Most of the participants replied that their economic condition is a barrier for them to seek care from a specialized hospital. As most of the participants are daily laborers, they are unable to go long distance by spending money and losing their daily wages.

We are poor, and it's difficult for us to meet the basic needs, our one-day earning is not enough to fulfil the basic needs; from where and how I will get 
Table 3 Comparison of public attitude score towards mental healthcare facilities by education level within gender

\begin{tabular}{|c|c|c|c|c|c|}
\hline Gender & Education & $N$ & Mean & SD & ANOVA " $p$ " value \\
\hline \multirow[t]{6}{*}{ Male } & Illiterate & 40 & 2.2 & 0.3 & \multirow[t]{5}{*}{0.001} \\
\hline & Primary (1-7) & 58 & 2.2 & 0.3 & \\
\hline & Secondary (up to 10th) & 70 & 2.0 & 0.5 & \\
\hline & Graduate and above & 30 & 2.0 & 0.4 & \\
\hline & Total & 198 & 2.1 & 0.4 & \\
\hline & \multicolumn{5}{|c|}{ Illiterate vs secondary (up to 10 th) ${ }^{*} p=0.005$, primary $(1-7)$ vs secondary (up to 10 th) ${ }^{*} p=0.006$} \\
\hline \multirow[t]{6}{*}{ Female } & Illiterate & 57 & 2.4 & 0.4 & \multirow[t]{5}{*}{0.000} \\
\hline & Primary $(1-7)$ & 41 & 2.4 & 0.4 & \\
\hline & Secondary (up to 10th) & 68 & 2.2 & 0.4 & \\
\hline & Graduate and above & 31 & 1.8 & 0.4 & \\
\hline & Total & 197 & 2.2 & 0.4 & \\
\hline & \multicolumn{5}{|c|}{$\begin{array}{l}\text { Illiterate vs secondary (up to } 10 \text { th) }{ }^{*} p=0.043 \text {, illiterate vs graduate and above }{ }^{*} p=0.000 \text {, primary (1-7) vs graduate and above }{ }^{*} p=0.000 \text {, } \\
\text { secondary (up to 10th) vs graduate and above } p=0.000\end{array}$} \\
\hline \multirow[t]{5}{*}{ Overall } & Illiterate & 97 & 2.3 & 0.4 & \multirow[t]{5}{*}{0.000} \\
\hline & Primary (1-7) & 99 & 2.3 & 0.3 & \\
\hline & Secondary (up to 10th) & 138 & 2.1 & 0.4 & \\
\hline & Graduate and above & 61 & 1.9 & 0.4 & \\
\hline & Total & 395 & 2.2 & 0.4 & \\
\hline
\end{tabular}

*Bonferroni " $p$ " value

thousands of rupees for treatment in a specific mental hospital.

\section{Discussion}

This study was done to find out the difference of attitudes with respect to the socio-demographic profile of the study participants. The key findings of the current mixed-method study among women from rural Odisha who participated in this study are summarized as follows: The women viewed a negative attitude towards the psychiatric hospitals and the factor associated with such kind of attitude was education and gender. And the qualitative findings showed that there were four major barriers among patients to seek care from mental health care facilities: the rejection of mental illness by patients due to fear of societal stigma, faith on magico-religious healers, lack of availability of mental health services, and poor socioeconomic conditions. A study conducted in India also revealed that factors such as lower education and females are having more of negative attitudes towards mental health care facilities [17, 22].

The present study suggested that females are best weakly related to the attitudes; they are slightly more rigid with their views and have more negative attitudes. A comparison study conducted in Canada highlighted that services provided by the psychiatric hospital are utilized more by male patients than the females [9], and the factors associated with such findings were low socioeconomic status and being single. Other studies conducted in India [11] and other developing countries [4] supported the above results.

Our study reported that a lower education was accompanied by more negative attitudes towards mental healthcare facilities across all subscales. While examining the issues related to the mental health system, it was always found that level of education is the key factor responsible for the attitudes [1]. Low education levels are responsible for gaps in mental health literacy and inadequate knowledge about seeking correct treatment, which could involve not approaching the appropriate mental health care facilities needed [22].

India, with its diverse cultural and ethical systems mixed in recent years with Western approaches of thinking, makes it tough to identify a uniform and exclusive Indian paradigm of mind and mental health [7]. In addition to this, receiving allopathy form of treatment does not necessarily imply the acceptance of all kinds of bio-medicine that support such therapies [12]. Mental illness can be cured using biomedicine and other traditional concepts such as Ayurveda. Supernatural and spiritual explanations are also standard practices such as evil-eye and spirit possession [9]. 
Table 4 Comparison of public attitude score towards mental healthcare facilities by education level within age group

\begin{tabular}{|c|c|c|c|c|c|}
\hline Age group in years & Education & $\mathbf{N}$ & Mean & SD & ANOVA " $p$ " value \\
\hline \multirow[t]{5}{*}{$<25$} & Illiterate & 1 & 2.43 & - & 0.045 \\
\hline & Primary (1-7) & 5 & 2.40 & 0.16 & \\
\hline & Secondary (up to 10th) & 22 & 2.05 & 0.48 & \\
\hline & Graduate and above & 32 & 1.86 & 0.43 & \\
\hline & Total & 60 & 1.98 & 0.46 & \\
\hline \multirow[t]{5}{*}{$25-34$} & Illiterate & 8 & 2.02 & 0.42 & 0.191 \\
\hline & Primary (1-7) & 27 & 2.28 & 0.34 & \\
\hline & Secondary (up to 10th) & 50 & 2.10 & 0.39 & \\
\hline & Graduate and above & 18 & 2.10 & 0.40 & \\
\hline & Total & 3 & 2.14 & 0.39 & \\
\hline \multirow[t]{5}{*}{$35-44$} & Illiterate & 12 & 2.29 & 0.32 & 0.046 \\
\hline & Primary (1-7) & 32 & 2.26 & 0.39 & \\
\hline & Secondary (up to 10th) & 38 & 2.01 & 0.45 & \\
\hline & Graduate and above & 4 & 2.07 & 0.36 & \\
\hline & Total & 86 & 2.15 & 0.42 & \\
\hline \multirow[t]{6}{*}{$45-54$} & Illiterate & 38 & 2.29 & 0.34 & 0.003 \\
\hline & Primary (1-7) & 27 & 2.28 & 0.35 & \\
\hline & Secondary (up to 10th) & 22 & 2.26 & 0.46 & \\
\hline & Graduate and above & 5 & 1.63 & 0.26 & \\
\hline & Total & 92 & 2.24 & 0.39 & \\
\hline & $\begin{array}{l}\text { Illiterate vs graduate anc } \\
\text { and above }{ }^{*} p=0.005\end{array}$ & & 7) vs gr & Dove & Condary (up to 10th) vs graduate \\
\hline \multirow[t]{6}{*}{$\geq 55$} & Illiterate & 38 & 2.41 & 0.36 & 0.001 \\
\hline & Primary (1-7) & 8 & 2.21 & 0.37 & \\
\hline & Secondary (up to 10th) & 6 & 1.74 & 0.60 & \\
\hline & Graduate and above & 2 & 1.79 & 0.30 & \\
\hline & Total & 54 & 2.28 & 0.44 & \\
\hline & \multicolumn{5}{|c|}{ Illiterate vs secondary (up to 10 th) ${ }^{*} p=0.002$} \\
\hline
\end{tabular}

*Bonferroni " $p$ " value

The qualitative result of the current study depicts that the study participants believe on faith healers, and most of these patients first contact the faith healers, then came to the allopathic practitioners which are similar in other studies [9]. Most of the cases first contacted the faith healers; if they did not get any relief, then only then, they move to other options like near to allopathic practitioner, traditional healers, etc. Generally, patients and their family members usually seek from different pathways, and these decisions are typically prejudiced by a number of factors, including socioeconomic status such as education [5].

While coming to the policy level, in the year 2015, World Health Organization has proposed two indicators to strengthen mental health in the Sustainable Development Goals; one is reducing the suicidal rate, and another one is service coverage of persons with severe mental illness, which are fully aligned with the Global
Mental Health Action plan [21]. Even in India, the Mental Health Act 2017 is introduced to make stronger the mental health by developing good infrastructure and other needed aspects, but in spite of the introduction of several policies and programmatic interventions over the past three decades, there is still only roughly one trained psychiatrist for every 250,000 people in India, and less than one of any sort of mental healthcare facilities for every 100,000 people. Although now people and communities are accepting the mental health care facilities in a positive way, still, negative beliefs and attitudes are present in their mind. Our study is addressing a need for awareness programs or strengthening the existing program to improve population, especially female attitude towards mental health care facilities. In addition, linking religious leaders to raise awareness about mental health care facilities could be important in India, where a lot of patients for mental illness seek care from priests and 
faith-healers. A possible drawback of our study is its focus on rural India only. Ideally, comparison studies with other countries and societies using a usual method should be carried out in the future.

Stigma can be divided into both public and selfstigma. Public stigma occurs when the general public supports a prejudice about a stigmatized group while self-stigma occurs when a member of a stigmatized group internalizes the negative sights held by the general public [19]. Given its negative impact on treatmentseeking, for instance, perceived social barriers may be particularly important in predicting treatment behaviors, such as taking an antidepressant, to remedy an illness whose victims may experience social stigma [18]. In addition to this, adherence and effectiveness, the stigma associated with mental illness can be considered as a major public health problem [15].

In India, a study revealed that patients attending psychiatric outpatient services at a mental hospital were asked specifically about various treatment facilities utilized by them before coming to the hospital and the reasons for. Various services used by the participants differ from professional care to faith healers. Easy availability, trust, recommendation from other patients and family, and belief in supernatural causation of illness were the significant factors for that. Thus, socio-cultural factors appeared to influence help-seeking behavior [10]. Stigma reduction is equally essential not only for those affected with mental illness and their families, but also for research, advocacy, and health policy globally [10].

The policy is required in this regard to understand the challenges and issues faced by a mentally ill individual and the process of overcoming it. It is very much significant to take account of stigma about mental illnesses and mental health issues. Stigma is disadvantageous not just to people with mental illness, but also to the health of society as a whole. Due to improper actions from the side of the public sector, mental health is facing problems, which also leads to a lack of resources and selfesteem for seeking appropriate care in mental illness. Not only lack of actions is responsible for the wrong health-seeking behavior, but also lack of leadership, legislation, institutions which are now in the stage of crumbling, lack of adequate information, and awareness are equally responsible. As mental health is always taken wrong by the people, creating awareness at the community level is the best weapon in the field of each and every sector of health. At a policy level, cultural and racial disparities can be addressed by considering the social factors like income, the standard of living, and education. In continuum, to this, a mental illness screening program and free mental health services should be initiated by the Govt. of India for early diagnosis and a better approach.
Due to this study's limitations, it is difficult to generalize the results of this study to the country as a whole. Furthermore, India is a country known to be ethnically and publicly diverse, and this research only looked at India's rural part. Further studies could broaden this subject of study by including other cities and states while also including larger sample size. Eventually, this analysis only evaluated behaviors toward a few factors against mental health care facilities. Instead of the exact value, we categorize the variable to decrease the anxiety among participants about sharing their age and education information, this also helps to increase care among them.

\section{Conclusion}

The community has different beliefs and opinions regarding mental health facilities, which is why increasing awareness among them will correct negativity. This study suggests that consideration should be given to the community's location, gender, and education when planning the awareness or implementation programs for mental health.

\section{Acknowledgements \\ The authors' gratitude and appreciation go to all the study participants. We do not have any financial support and sponsorship.}

\section{Authors' contributions}

Collection of data: S.J, K.P, C.S, and H.A. Writing of the manuscript or general supervision of the research group: K.C.S, S.J, P.M, and S.P. The manuscript was approved by all authors.

\section{Funding}

No funding.

Availability of data and materials

All the raw data are available with the authors.

Ethics approval and consent to participate

This study was approved by the ethics committee of Asian Institute of Public Health, Odisha, India with approval number: ERC/ No: 2016-02. The participants were provided written consent.

\section{Consent for publication}

The consent for the publication was obtained from the participants.

\section{Competing interests}

There are not any competing interests for this study.

\section{Author details}

${ }^{1}$ All India Institute of Medical Sciences, Bhubaneswar, Odisha 751019, India. ${ }^{2}$ Regional Medical Research Centre, Indian Council of Medical Research, Bhubaneswar, Odisha 751023, India. ${ }^{3}$ National Health Mission, Raipur, Chhattisgarh 492017, India. ${ }^{4}$ Odisha Social Sciences Research Consultancy, Bhubaneswar, Odisha 751003, India. ${ }^{5}$ Kalinga Institute of Medical Sciences, Bhubaneswar, Odisha 751024, India.

Received: 28 May 2020 Accepted: 10 September 2020

Published online: 10 November 2020

\section{References}

1. Chisholm D (2015) Investing in mental health. Eastern Mediterranean Health J 21(7):531-534. https://doi.org/10.1093/heapro/dar059 
2. Dąbrowski, A. (2011). General information. SPA 2011 - Signal Processing: Algorithms, Architectures, Arrangements, and Applications - Conference Proceedings, 107, 5. https://doi.org/10.1525/california/9780520268807.003. 0006.

3. Gaebel W, Zäske H, Zielasek J, Cleveland H-R, Samjeske K, Stuart H et al (2015) Stigmatization of psychiatrists and general practitioners: results of an international survey. Eur. Arch. Psychiatry Clin. Neurosci. 265, 189-197. https://doi.org/10.1007/s00406-014-0530-8

4. Gur K, Kucuk L (2016) Females' attitudes toward mental illness: a sample from rural Istanbul, Turkey. Iranian Red Crescent Med J 18(5). https://doi.org/ 10.5812/ircmj.22267

5. Ibrahim A, Hor S, Bahar OS, Dwomoh D, McKay MM, Esena RK, Agyeponge IA (2016) Pathways to psychiatric care for mental disorders: a retrospective study of patients seeking mental health services at a public psychiatric facility in Ghana. Int J Mental Health Syst 10(1):1-11. https://doi.org/10.1186/ s13033-016-0095-1

6. Kandeger A, Guler HA, Egilmez U, Guler O (2018) Major depressive disorder comorbid severe hydrocephalus caused by Arnold - Chiari malformation. Does exposure to a seclusion and restraint event during clerkship influence medical student 's attitudes toward psychiatry ? Indian J Psychiatry 59(4): 2017-2018. https://doi.org/10.4103/psychiatry.IndianJPsychiatry

7. Kermode M, Herrman H, Arole R, White J, Premkumar R, Patel V (2007) Empowerment of women and mental health promotion : a qualitative study in rural Maharashtra. India 10:1-10. https://doi.org/10.1186/1471-24587-225

8. Kishore J, Gupta A, Jiloha RC, Bantman P (2011) Myths, beliefs and perceptions about mental disorders and health-seeking behavior in Delhi, India. Indian J Psychiatry 53(4):324-329 https://doi.org/10.4103/0019-5545. 91906

9. Lahariya C, Singhal S, Gupta S, Mishra A (2010) Pathway of care among psychiatric patients attending a mental health institution in central India. Indian J Psychiatry 52(4):333 https://doi.org/10.4103/0019-5545.74308

10. Lauber C, Rössler W (2007) Stigma towards people with mental illness in developing countries in Asia. Int Rev Psychiatry 19(2):157-178 https://doi. org/10.1080/09540260701278903

11. Malla AK, Norman RM (1983) Mental hospital and general hospital psychiatric units: a comparison of services within the same geographic area. Psychological Med 13(2):431-439

12. Nunley M (1988) The involvement of families in Indian psychiatry, 317-318

13. Panigrahi A, Padhy AP, Panigrahi M (2014) Mental health status among married working women residing in Bhubaneswar City, India: a psychosocial survey. BioMed Res Int 2014:1-7 https://doi.org/10.1155/2014/979827

14. Rehm J, Shield KD (2019) Global burden of disease and the impact of mental and addictive disorders. Current Psychiatry Reports 21(2) https://doi. org/10.1007/s11920-019-0997-0

15. Rüsch, N., Abbruzzese, E., Hagedorn, E., Hartenhauer, D., Kaufmann, I., Curschellas, J., ... Corrigan, P. W. (2014). Efficacy of coming out proud to reduce stigma's impact among people with mental illness: pilot randomised controlled trial. British J Psychiatry, 204(5), 391-397. https://doi.org/10.1192/ bjp.bp.113.135772

16. Sagar R, Dandona R, Gururaj G, Dhaliwal RS, Singh A, Ferrari A et al (2020) The burden of mental disorders across the states of India: the Global Burden of Disease Study 1990-2017. Lancet Psychiatry 7(2):148-161. https:// doi.org/10.1016/S2215-0366(19)30475-4

17. Sharma, P., Banwari, G., Chaudhary, P., Gandhi, H., \& Parikh, N. (2014). Study of attitude of interns toward psychiatry: A survey of a tertiary level hospita in Ahmedabad. Industrial Psychiatry Journal, 23(2), 143. https://doi.org/10. 4103/0972-6748.151690.

18. Sirey JA, Bruce ML, Alexopoulos GS, Perlick DA, Friedman SJ, Meyers BS (2001) Stigma as a barrier to recovery: perceived stigma and patient-rated severity of illness as predictors of antidepressant drug adherence. Psychiatric Serv 52(12):1615-1620 https://doi.org/10.1176/appi.ps.52.12.1615

19. Venkatesh B, Andrews T, Mayya S, Singh M, Parsekar S (2015) Perception of stigma toward mental illness in South India. J Fam Med Primary Care 4(3): 449 https://doi.org/10.4103/2249-4863.161352

20. WHO (2003) World Health Report 2002 - Reducing risks, promoting healthy life Methods Summaries for Risk Factors assessed in Chapter 4. World Health Report (1994):1-33

21. World Health Organization. (2013). Mental health action plan 2013-2020. WHO Library Cataloguing-in-Publication DataLibrary Cataloguing-inPublication Data, 1-44. https://doi.org/ISBN 9789241506021
22. Zieger A, Mungee A, Schomerus G, Ta TT, Dettling M, Angermeyer M, Hahn E (2016) Perceived stigma of mental illness: a comparison between two metropolitan cities in India. Indian J Psychiatry 58(4):432 https://doi.org/10. 4103/0019-5545.196706

\section{Publisher's Note}

Springer Nature remains neutral with regard to jurisdictional claims in published maps and institutional affiliations.

\section{Submit your manuscript to a SpringerOpen ${ }^{\circ}$ journal and benefit from:}

- Convenient online submission

- Rigorous peer review

- Open access: articles freely available online

High visibility within the field

- Retaining the copyright to your article

Submit your next manuscript at $\boldsymbol{\nabla}$ springeropen.com 